\title{
Gramatika orokorra eta arrazoitua [Hainbat zati]
}

\author{
Antoine Arnauld eta Claude lancelot \\ Grammaire Générale et Raisonnée [Selected Chapters]. 1660.
}

Itzultzailea: Jesus Mari Larrazabal ${ }^{1}$

DOI: $10.1387 /$ gogoa.19742

\section{Itzultzailearen aitzin oharra}

Honako itzulpen hau horixe da: itzulpen soila, ohar kritikorik gabea. Port-Royaleko Gramatika 1660an eman zen argitara, eta honako hauek izan ziren egileak: Antoine Arnauld (1612-1694) filosofo eta logikaria (jansenista) eta Claude Lancelot (1615-1695) gramatikaria; latina, grekoa eta espainola erakusteko Metodoen egile ezaguna. Nik, itzulpen hau egiteko, 1676an argitaratutako edizioaren erreprodukzioa erabili dut. Hizkuntzalari eta hizkuntzazale frantsesek ongi ezagutzen dute Gramatika hau. Baina gure Huarte Donibanekoaren Examen de Ingenios (1575) liburuaren antzera, Gramatika hau ezagunago bihurtu da gaur munduan zehar Noam Chomskyri esker. Chomskyk, Cartesian Linguistics liburuan (1966), Huarteren liburuak Descartesengan agian eragina izan zuela esan ondoren, luze hitz egiten du Port-Royaleko Gramatikaz (eta Port-Royaleko Logikaz). Sakoneko eta azaleko egiturak bereizteko, eta, ondoren, lotzeko, oso baliagarri egiten zaio Gramatika hau. Descartesen hizkuntzaren filosofia arrazionalistaren ildoa argi dago, bai Gramatikan, bai Logikan. Ongi azpimarratzen du hori Chomskyk. Azpimarratzekoa da, baita ere, gramatika eta logika eskolastikoaren eragina, bai batean eta bai bestean.

Antoine Arnauld eta Pierre Nicolek (1625-1695) idatzi zuten Logika edo Pentsatzearen Artea (1662), modu anonimoan argitaratua eta, besterik gabe, Port-Royaleko Logika gisa ezagutua. Bi diskurtso eta lau zati ditu

\footnotetext{
${ }^{1}$ Itzulpen honen lehenagoko bertsioa hemen argitaratu zen, 2004an: Gogoa IV (1): 9-20.
} 
Logika horrek. Zatietan honako hauxe: terminoen logika, judizioen logika, arrazonamenduaren logika eta zientziaren logika (hau da, ordenamenduaren metodologia).

Gramatikak bi zati ditu, eta bigarrenaren lehen kapituluan gogoak hiru eragiketa egiten dituela esaten zaigu: kontzebitzea, juzgatzea eta arrazoitzea. Bi urte geroago azaldu zen Logikak honelaxe dio lehen zatiaren hasieran (edo bigarren diskurtsoaren amaieran, edizioen arabera): «La Logique est l'Art de bien conduire sa raison dans la connoissance des choses, tant pour s'en instruire soi-même, que pour en instruire les autres. Cet Art consiste dans les réflexions que les hommes ont faites sur les quatre principales opérations de leur esprit, concevoir, juger, raisonner, \& ordonner». Hemen dago berrikuntza. Aristotelesek lehen hiru eragiketetarako Kategoriak, Interpretazioaz eta Lehen Analitikoak idatzi zituen, logikaren eginkizun nagusia («ondorioa» zer den aztertu eta mugatzea) hirugarren liburuari lotuz. Geroztik, halaxe egin izan du logika tradizionalak eta XIX. mendearen bigarren erditik aurrera ondorio izatearen azterketari heldu dio soilik; eta, horrela, ontologiarekiko eta ezagutzaren teoriarekiko autonomia indartu du logikak.

Ordenatzeak, metodoak, garrantzia hartzen du Port-Royal-des-Champsekoentzat. Logika ezagutzaren teoriarekin erabat uztartuta dator, eta eginkizun berezia ematen zaio metodoari (Logikaren laugarren zatia), arrazionalismoa zintzo praktikatuz, espiritu geometrikoaren ildoa zabaltzeko, bai egien aurkikuntzan, bai aurkitutako egien azalpenean (hau da, jakintzaren transmisioan). Horregatik, laugarren zati horretan egiten da definizioen teoria, axiomen teoria, frogen teoria eta zientziaren metodoaren teoria. Azken hori zortzi erregela nagusitara murrizten da, aurreko lau teoria horietako bakoitzarentzat bina; honako bi erregela berezi hauek dira metodoarentzat proposatutakoak: (1) ordena naturala erabili, sinple eta orokorretik espezie partikularrei dagozkien zehaztapenetara joz; eta (2) genero bakoitza bere espezie guztietan, osotasun bakoitza bere zati guztietan eta zailtasun bakoitza bere kasu guztietan zatitu.

Horixe da, funtsean, ezagutzan arrazoiz jokatzea arrazionalistentzat. Gramatikan gauza bera. Nik itzuli ditudan zati aukeratu hauek Port-Royaleko (gure Saint-Cyrango abadea (1581-1643) barne) Gramatikaren metodoaren aztarnak zertxobait azaltzeko balio badute, ongi betea legoke egindako ahaleginaren balioa.

[Oharra: Claude Lancelotek egin zuen Gramatikaren hitzaurrea] 


\section{GRAMATIKA OROKORRA ETA ARRAZOITUA}

\section{Hitzaurrea}

NIK aukeratuta baino areago halaxe tokatuta, hizkuntza ezberdinen Gramatikak lantzeko daukadan konpromisoak sarritan eraman nau hizkuntza guztiek batean dituzten edo bakarren batzuei berezi zaizkien gauza batzuk ikertzera: baina maiz lan horretan geldiarazten ninduten zailtasunak aurkitzen nituenez, nire lagun bati komunikatu dizkiot geure enkontruetan. Zientzia-modu honetan sekula aritu ez izan arren, nire zalantzak konpontzeko argibide asko ematen segitu du berak; eta nire galdera horiexek hitz egiteko artearen benetako oinarriei buruzko gogoeta ezberdin batzuk eragin dizkiote, elkarrizketan erabiliak. Hain pisuzko jotzen nituen, galtzen uzteko arriskuaz ohartu bainintzen, ez antzinako gramatikariengan, ezta berriengan ere, izan ere, ez dut ikusi gauza jakingarriago eta zuzenagorik gai horretaz. Horrexegatik, berak niretzat oraindik duen ontasuna lortu nuen, eta ordu galduetan diktatu zizkidan; eta, horrela, jaso eta ordenatuz, horiekin tratatu txiki hau konposatu dut. Arrazonamenduari buruzko lanei estimua dietenek honako honetan topatuko dute agian aseko dituen zerbait, eta ez dute gaia gutxietsiko. Zeren hizketa baldin bada gizakiaren abantaila handienetako bat, ezin baita gutxiesteko gauza izan gizakiari dagokion perfekzio guztiarekin abantaila horren jabe izatea; abantaila hori ez baita bakarrik hizketaren erabileraren mailakoa, baizik horren arrazoietan sartzeko eta besteek ohituraz bakarrik egiten dutena zientziaz egiteko.

\section{Gramatika orokorra eta arrazoitua}

GRAMATIKA hitz egitearen artea da.

Hitz egitea pentsamenduak esplikatzea da, horretarako gizakiek asmatu dituzten zeinuak erabiliz.

Zeinuen artean erosoenak soinuak eta ahotsak zirela aurkitu zuten.

Soinu horiek iragan egiten direnez, ordea, beste zeinu batzuk asmatu zituzten, iraunkorrago eta ikusgarriago izan zitezen; idazkuntzaren karakte-

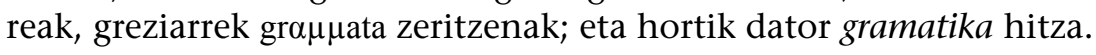

Horrela, zeinu horietan bi gauza har daitezke kontuan. Lehena: berez zer diren; hau da, soinu eta karaktere gisa.

Bigarrena: beren esanahia; hau da, gizakiek beren pentsamenduak esan nahi izateko duten era.

Bata Gramatika honen lehen zatian aztertuko dugu eta, bestea, bigarrenean. 


\section{LEHEN ZATIA}

\section{Non letrez eta idazkuntzaren karaktereez hitz egiten baita}

\section{$[\ldots]$}

\section{KAPITULUA}

\section{Letrez, karakteretzat hartuta}

ORAIN arte ez dugu letrez hitz egiterik izan, haien karaktereek markatzen dituzten heinean ez bada. Baina, haatik, ez ditugu letrak karakteretzat hartu; hau da, karaktereek soinuekin duten harremanaren arabera.

Esana dugu jada gizakiek soinuak hartu dituztela pentsamenduen zeinu izateko eta figura batzuk asmatu dituztela halaber soinu horien zeinu izateko. Figura edo karaktere horiek, beren lehen instituzioaren arabera, zuzenean soinua bakarrik esan nahi badute ere, gizakiek sarritan eramaten dituzte beren pentsamenduak karaktereetatik soinuak esan nahi izandako gauzara bertara. Hortaz, karaktereak bi eratan har daitezke: soinua soilik esan nahi dute, edo soinuak esan nahi duena kontzebitzeko lagungarri dira.

Lehen eran hartuz gero, beren perfekzioan jartzeko lau gauza izango dira bete beharrekoak.

1. Figura guztiek soinuren bat markatzea; hau da, ahoskatu gabeko ezer ez idaztea.

2. Soinu guztiak figuraren batek markatua izan behar du; hau da, ez da ezer ahoskatuko idatzitakoa ez bada.

3. Figura bakoitzak soinu bat baino gehiago ez du markatuko, soinu sinplea edo bikoitza. Ez doalako idazkuntzaren perfekzioaren aurka letra bikoitzak izatea, idazketa laburtuz, erraztu egiten baitute.

4. Ez da markatuko soinu bera figura ezberdinen bidez.

Aitzitik, karaktereak bigarren eran hartuz gero — hau da, soinuak esan nahi duena kontzebitzeko lagungarritzat - batzuetan abantailazkoa zaigu erregela horiek beti ez betetzea; batez ere lehen eta azken erregelak.

Sarri askotan gertatzen baita, batez ere beste hizkuntzetatik eratorritako hizkuntzetan, badirela ahoskatzen ez diren letra batzuk, eta, horrela, soinuari dagokionez alferrikakoak dira eta baliagarriak hitzek esan nahi dutena ulertzeko. Adibidez, champs eta chants hitzetan, $p$ eta $t$ ez dira ahoskatzen, baina esanahiarentzat baliagarriak dira, hortik ikasten dugulako lehenbizikoa latineko campitik eta bigarrena latineko cantusetik datorrela. 
Hebreeran bertan badira hitzak elkarrengandik bereizten direnak bata aleph batez bukatzen delako eta bestea he batez bukatzen delako bakarrik, nahiz eta ez bata ez bestea ahoskatzen diren: esaterako, À ${ }^{\prime}$-ek beldur izan esan nahi du, eta ${ }^{\prime}$ '-ek bota esan nahi du.

Eta horretan ikusten da ahoskatu ez bezala idazteari buruz hain kexu direnek ez dutela beti arrazoi handirik, eta gehiegizko erabilera esaten dioten hori ez dela batzuetan alferrikakoa.

Badirudi letra larrien eta xehen arteko ezberdintasuna laugarren erregelaren kontra doala; hau da, soinu bera beti figura berak markatzea. Eta, izan ere, hori alferrikakoa izango litzateke zeharo, karaktereak soinuak markatzeko bakarrik hartuko bagenitu, letra larri eta xehe batek soinu bera baitute. Hortik dator antzinakoek ezberdintasun hori ez izatea, hebrearrek gaur oraindik ez duten bezala, eta bakarren batzuek uste izatea greziarrek eta erromatarrek luzaz letra larriz baizik ez zutela idatzi. Hala ere, bereizketa hau arras baliagarria da periodoak hasteko eta izen propioak besteetatik bereizteko.

Hizkuntza batean bertan ere badaude idazkuntza mota ezberdinak, latina eta hizkuntza arrunt batzuk inprimatzerakoan erabiltzen diren erromatarra eta italikoa, esaterako; modu baliagarrian erabil daitezke zentzuarentzat, hainbat hitzetan edo hainbat diskurtsotan bereizketak eginez, nahiz horrek ahoskatzean ez duen deus aldatzen.

Horra bada ahoskatzearen eta idazkeraren artean aurkitzen den aldea zuritzeko esan dezakeguna; baina honek ez du eragozten esatea bereizketa batzuk arrazoirik gabe egin direla, hizkuntzetan irristaz sartu den korrupzioaren eragin hutsez. Gehiegikeria baita, adibidez, $c$, $e$-ren eta $i$-ren aurrean, $s$ gisa ahoskatzea; bi bokal horiexen aurrean, eta ez besteen aurrean, $g$ beste modu batean ahoskatzea; $s$ leuntzea bi bokalen artean; jarraian beste bokal bat duen $i$-ren aurrean, $t$-ri $s$-ren soinua ematea; esaterako, gratia, actio, action. Honetaz Nouvelle Méthode latinen dagoen letren tratatuan esandakoa ikus daiteke.

Batzuek akats hori hizkuntza arruntetan zuzendu zezaketela uste izan dute, karaktere berriak asmatuz Ramusek frantses hizkuntzarentzat egindako gramatikan bezala, ahoskatzen ez diren guztiak kenduz eta soinu bakoitza bere ahoskatzeari dagokion letraz idatziz, hala nola $e$-ren eta $i$-ren aurrean $c$ ren ordez $s$ jarriz. Baina horiek honako hau hartu behar zuten kontuan: maiz hizkuntza arruntentzat abantailarik gabekoa izateaz gain, esandako arrazoiengatik, ezinezko gauza baten atzetik zebiltzala; ez delako pentsatu behar erraza denik nazio oso bati aspalditik ohiko zaizkion hainbeste karaktere aldaraztea, Klaudio enperadore berak ezin izan baitzuen lortu berak erabiltzea nahi izan zuen karaktere bat sartzea.

Honako hauxe da arrazoiz egin litekeen guztia: ez ahoskatzeko, ez zentzurako, ez hizkuntzen analogiarako baliagarri ez diren letrak kendu, orain 
egiten hasi den bezala; eta, baliagarri direnak gordez, hauei marka txiki batzuk jarri, ez direla ahoskatzen ikusarazteko, edo letra beraren ahoskatze ezberdinak ezagutarazteko. Letraren barruan edo azpian puntu bat jartzeak lehen erabilerarako balio lezake, tempsen bezala. $c$-k badu jada bere ze hautsia, $e$-ren eta $i$-ren aurrean eta beste bokalen aurrean ere erabil genezakeena. $g$-k $e$-ren eta $i$-ren aurrean duen soinua marka genezake $g$-ren isatsa erabat itxi gabe. Adibide bat besterik ez da hori.

\section{KAPITULUA}

\section{Edozein hizkuntzatan irakurtzen erraz ikasteko era berriaz}

METODO hau oraindik irakurtzen ez dakitenei zuzendua da bereziki.

Egia da hasiberrientzat ez dela ahalegin handia besterik gabe letrak ezagutzea; ahaleginik handiena letrak lotzea da, ordea.

Orain, honako hauxe da lan hori zailago bihurtzen duena, letra bakoitzak bere izena izanik, beste batzuekin lotuta bakarrik ahoskatzen dela. Adibidez, haur bati fry lotuarazten bazaio, ef(e), er(re), i[y] grekoa ahoskarazten zaio; horrek nahastu egiten du ezinbestez, ondoren, hiru soinu horiek elkarrekin jarriz, fry silabaren soinua egin nahi duenean.

Beraz, badirudi honako hauxe dela biderik naturalena, jende argi eta burutsu batek jada azpimarratu duen bezala: irakurtzen erakusten dutenek hasieran ez liekete haurrei letrak ezagutzen irakatsi behar, ez bada horiek ahoskatzeko izenen bidez. Eta, horrela, latinez irakurtzen ikasteko, adibidez, $e$-ren izen bera eman $e$ sinpleari, ae-ri eta oe-ri, era berean ahoskatzen direlako; eta berdin $i$-ri eta $y$-ri; eta baita $o$-ri eta $a u$-ri ere, gaur Frantzian ahoskatzen denaren arabera, italiarrek $a u$ diptongo bihurtzen dute eta.

Kontsonanteak ere beren soinu naturalez izendatu beharko lirateke, $e$ mutua bakarrik erantsiz, ahoskatzeko beharrezkoa dena: adibidez, $b$-ri izena emateko tombe-ren azken silaban ahoskatzen dena hartuko genuke; $d$-ri izena emateko ronde-ren azken silabari dagokiona; eta horrela soinu bakarra duten besteekin ere.

Soinu bat baino gehiago dutenei $-c, g$, $t$ eta $s$-k duten bezala-, berezko soinu natural eta arruntenarekin deitu beharko genieke: $c$-ri que soinuarekin, $g$-ri gue-rekin, $t$-ri forte-ren azken silabaren soinuarekin, eta s-ri bourse-ren azken silabarenarekin.

Eta ondoren $c e, c i$, ge, gi, tia, tie, tii silabak aparte eta letreiatu gabe ahoskatzen irakatsi beharko litzaieke. Eta bi bokalen arteko $s z$ baten moduan ahoskatzen dela entzunaraziko genieke, miseria, misère, mizeria, mizère bagenu bezala, eta abar. 
Horra bada irakurtzen irakasteko metodo berriaren betebehar orokorrenak. Metodo hori oso baliagarria izango da, ziur, haurrentzat. Baina bere perfekzio osoan jartzeko, aparteko tratatu txiki bat egin beharko litzateke; hizkuntza guztiei egokitzeko beharrezko oharrak egin ahal izango lirateke bertan.

\section{BIGARREN ZATIA}

\section{Non hitzen esanahiaren forma ezberdinen euskarri diren printzipio eta arrazoiez hitz egiten baita}

\section{LEHEN KAPITULUA}

Gramatikaren oinarriak ulertzeko beharrezkoa dela gure gogoan gertatzen dena ezagutzea; eta diskurtsoa osatzen duten hitzen ezberdintasuna horren araberakoa dela

ORAIN arte, hizketaren alde materialaz soilik arduratu gara eta, gutxienez soinuari dagokionean, gizaki eta loroek batean dutena bakarrik hartu dugu kontuan.

Aztertzeko geratzen zaiguna bere alde espirituala da, hau da gizakiak beste animalia guztien gainean duen abantaila handienetakoa eta arrazoiaren froga handienetakoa: gure pentsamenduak adierazteko egiten dugun erabilera, eta honako asmakuntza zoragarria, hogeita bost edo hogeita hamar soinurekin hitzen aniztasun infinitu hori osatzeko gaitasuna (hitz horiek ez dute beren baitan gure espirituan gertatzen denaren batere antzik eta, halere, besteei gure sekretu osoa azaltzeko gauza dira) eta gure ariman sartu ezin direnei kontzebitzen dugun guztia eta arimaren mugimendu ezberdin guztiak ulertaraztekoa.

Honela defini daitezke hitzak: soinu ezberdin eta artikulatuak, gizakiek beren pentsamenduak adierazteko zeinu bihurtu dituztenak.

Horregatik, ezin dira ongi ulertu hitzetan gorderik dauden mota ezberdinetako esanahiak, aurretik ez bada ongi ulertzen gure pentsamenduetan gertatzen dena; horiek ezagutarazteko asmatu baitira hitzak.

Filosofo guztiek gure espirituan hiru eragiketa daudela erakutsi dute: KONTZEBITU, JUZGATU, ARRAZOITU.

KONTZEBITZEA honako hauxe besterik ez da: gure espirituak gauzei begiratu sinplea ematea, era intelektual soilean (nik izatea, iraupena, pentsamendua, Jainkoa ezagutzen ditudanean bezala) edo gorputzaren irudien bidez (karratua, biribila, zakurra, zaldia irudikatzen ditudanean bezala). 
JUZGATZEA honako hauxe da: guk kontzebitzen dugun gauza bat hori den edo ez den baieztatzea, lurra zer den eta biribiltasuna zer den kontzebitu ondoren, lurra biribila dela baieztatzen denean bezala.

ARRAZOITZEA honako hauxe da: bi judizioren bitartez hirugarren bat egitea; esaterako, bertute guztiak laudagarri direla juzgatzen denean eta pazientzia bertutea dela, hortik pazientzia laudagarria dela ondorioztatzen dudanean bezala.

Hortik ikusten da espirituaren hirugarren eragiketa bigarrenaren hedapena besterik ez dela; eta, beraz, gure gairako, aski dela lehen bi eragiketak kontuan hartzea, edo bigarrenean lehenbizikotik gorderik dagoena. Izan ere, gizakiek ez dute ia inoiz kontzebitzen dutena bakarrik adierazteko hitz egiten, baizik eta ia beti kontzebitzen dituzten gauzei buruzko judizioak adierazteko.

Gauzei buruz egiten dugun judizioari, esaterako lurra biribila da diogunean, PROPOSIZIOA esaten zaio. Eta, horrela, edozein proposiziok bi termino ditu nahitaez: bata subjektu deitua, horri buruz baieztatzen dugu, esaterako lurra; eta, bestea, atributo deitua, baieztatzen den hori, esaterako biribila. Eta, gainera, bi termino horien arteko lotura: $d a$.

Orain, erraza da ikusten bi terminoak espirituaren lehen eragiketari dagozkiola, horixe delako guk kontzebitzen duguna eta horixe gure pentsamenduaren objektua; eta lotura bigarrenari dagokiola, gure espirituaren berezko ekintza eta pentsatzeko dugun era dela esan dezakeguna.

Eta, horrela, gure espirituan gertatzen den bereizketarik handiena gure pentsamenduaren objektua eta forma edo modua kontsideratu ahal izatea da; azken horren era nagusia judizioa da. Baina horri erantsi behar zaizkio konjuntzioak, disjuntzioak eta gure espirituaren antzeko beste eragiketa batzuk, eta gure arimaren beste mugimendu guztiak; hala nola, desirak, aginduak ematea, galdetzea, eta abar.

Honako hau ondorioztatzen da hortik: gizakiek beren espirituetan gertatzen den guztia markatzeko zeinuak behar dituztenez, hitzen arteko bereizketarik orokorrena ere behar dutela, hitz batzuek gure pentsamenduen objektuak adierazteko eta beste batzuek gure pentsamenduen forma eta modua; nahiz berauek bakarrik maiz esanahirik ez izan, objektuarekin baizik, geroago erakutsiko dugun bezala.

Lehen motako hitzak izenak, artikuluak, izenordainak, partizipioak, preposizioak eta adberbioak dira; bigarren motakoak aditzak, konjuntzioak eta interjekzioak; guztiak derrigorrezko jarraipen batetik datoz, gure pentsamenduak adierazteko darabilgun modu naturaletik, gero erakutsiko dugunez.

$$
[\ldots]
$$




\section{KAPITULUA}

\section{Sintaxiaz, edo hitzen joskeraz}

SINTAXIAZ edo hitzak elkarrekin josteaz zerbait esatea geratzen da. Ez da zaila izango nozio orokorrak ematea, mugatu ditugun printzipioei jarraituz.

Hitzak jostean, oro har, honako bereizketa hau egiten da: bat etortzea, hitzek bat etorri beharra dutenean; eta erregimena, hitz batek bestean aldaketa eragiten duenean.

Lehenbizikoa, neurri handi batean, berdina da hizkuntza guztietan, diskurtsoa hobeto bereizteko ia edonon erabili ohi denaren jarraipen naturala baita.

Horrela, bi numeroren bereizketak, singularra eta plurala, substantiboa adjektiboarekin numeroan komunztatzera behartzen du; hau da, bata singular edo pluralean jartzera, bestea horrela denean. Substantiboa adjektiboak nahasian, baina zuzenean, markatzen duen subjektua denez, substantiboa den hitzak bat baino gehiago markatzen badu, adjektiboak markatutako erako subjektu bat baino gehiago dago eta, ondorioz, pluralean egon behar du: Homines docti, hommes doctes, gizon jakintsuak.

Maskulinoaren eta femeninoaren arteko bereizketak, era berean, substantiboa eta adjektiboa genero berean jartzera behartzen du, edo bata eta bestea, batzuetan, neutroan, horrelakorik duten hizkuntzetan; horretarako, eta ez beste ezertarako, asmatu baitira generoak.

Horrelaxe, aditzek ere bat etorri behar dute izen eta izenordainekin numeroan eta pertsonan.

Horrela bada, itxuraz erregela horien aurkako zerbait topatzen bada, figurarengatik da; hau da, hitzen bat aurretik ulertuz, edo hitzak berak ez baina pentsamenduak kontuan hartzeagatik, geroago hementxe esango dugun moduan.

Alderantziz, erregimenaren sintaxia arbitrarioa da ia osorik, eta arrazoi horregatik oso ezberdina da hizkuntza guztietan. Izan ere, batzuek kasuen bidez egiten dituzte erregimenak; besteek, kasuen ordez, horien lekua hartzen duten partikula txikiak erabiltzen dituzte, kasu horietako oso gutxi markatzen dituztenak. Esaterako, frantsesez eta espainieraz, genitiboa eta datiboa markatzeko de eta à bakarrik daude; italiarrek horiei da eransten diete ablatiboarentzat. Beste kasuek ez dute partikularik, artikulu soila baizik; gainera, hori ere ez dago beti.

Gai horretaz hor goian preposizio eta kasuez esan duguna ikus dezakegu. Baina egokia da maxima orokor batzuk azpimarratzea, hizkuntza guztietan asko erabiltzen direnak. 
Lehena, ez dagoela sekula nominatiborik adierazitako edo jakintzat emandako aditzen batekin harremanik ez duenik, ez baita hitz egiten kontzebitzen dena markatzeko soilik, baita kontzebitutakoaz pentsatzen dena adierazteko ere; aditzaren bidez markatzen da hori.

Bigarrena, ez dagoela halaber aditzik bere nominatiboa adierazita edo jakintzat emana ez duenik; aditzari dagokiona baieztatzea denez, baieztatzeko zerbaitek egon behar du, subjektua edo aditzaren nominatiboa dena, nahiz eta infinitiboen aurrean akusatiboan azaldu: Scio Petrum esse doctum.

Hirugarrena, ezin daitekeela egon substantiboren batekin harremanik ez duen adjektiborik, adjektiboak nola edo hala substantibo bat markatzen duelako; substantibo hori adjektibo horrek garbi markatzen duen formaren subjektua da: doctus, savant, (jakintsua), jakintsua den norbaitekin dago harremanean.

Laugarrena, diskurtsoan ez dagoela inoiz izenen batek gobernatzen ez duen genitiborik; kasu horrek beti jabea-edo markatzen duenez, beharrezkoa da jabetzapeko gauzaren gobernuari lotua egotea. Horregatik, ez dago ez grekoan ez latinean zehazki genitiboa gobernatzen duen aditzik, bi hizkuntza horientzako Metodo Berrietan ikusarazi denez. Erregela hori hizkuntza arruntei aplikatzea zailago egiten da, de partikula, genitiboaren marka, ex edo de preposizioen ordez jartzen baita askotan.

Bosgarrena, maiz aditzen erregimena kasuetan gordeta dauden harreman mota ezberdinetatik hartua dagoela, ohituraren nahieraren arabera; horrek ez du kasu bakoitzaren harreman berezia aldatzen, baina agerrarazten du ohiturak aukera bat edo bestea egin duela bere nahierara.

Horrela, latinez esaten da juvare aliquem, eta opitulari alicui, nahiz biak laguntza adierazten duten aditzak izan, latindarrei gustuko egin zitzaielako lehen aditzaren erregimena bere ekintza pasatzen den terminoa bezala begiratzea, eta bigarrenarena atribuzio kasu bezala hartzea; aditzaren ekintzak harremana zuen atribuzio horrekin.

Horrela, frantsesez servir quelqu'un eta servir à quelque chose esaten da.

Horrela, espainieraz aditz aktibo gehienek berdin gobernatzen dute datiboa edo akusatiboa.

Horrela, aditz berak erregimen ezberdinak jaso ditzake, batez ere preposizioekin konbinatuz; esaterako, praestare alicui, edo aliquem, norbait gainditu.

Horrela, adibidez, eripere morti aliquem, edo mortem alicui, edo aliquem a morte, eta antzekoak esaten dira.

Batzuetan, gainera, erregimen ezberdin horiexek adierazpenaren zentzua aldatzeko indarra dute, hizkuntzaren erabilerak hala baimendu badie: adibidez, latinez cavere alicui norbait zaintzea da, eta cavere alicuem norbaite- 
kin kontuz ibiltzea; hortaz, hizkuntza guztietan egiten den erabilera aztertu behar da beti.

\section{Joskera figurez}

Hemen goian sintaxiaz esan duguna nahikoa da bere ordena naturala ulertzeko, diskurtsoaren zati guztiak sinpleki adierazita daudenean, hitz bakar bat ere ez dagoenean ez soberan ez faltan eta diskurtsoa gure pentsamenduen adierazpen naturalarekin bat datorrenean.

Alabaina, gizakiek sarri askotan pentsamenduen zentzuari gehiago segitzen diote horiek adierazteko baliatutako hitzei baino, eta maiz diskurtsoari zerbait kentzen diote laburtzeko, edo, dotorezia kontuan hartuz, alferrikako dirudien hitzen bat lagatzen dute, edo ordena naturala iraultzen dute. Hortik etorri da hitz egiteko lau modu gogoan hartzea, figuratuak esaten zaienak, eta gramatikan irregulartasunen antzeko direnak; nahiz hizkuntzan, batzuetan, perfekzio eta edertasun izan.

Diskurtsoaren hitzekin baino gehiago gure pentsamenduekin bat datorrenari SILEPSIA edo kontzepzioa deritzo. Esaterako, il est six heures diodanean; ezen, hitzen arabera, beste hau esan beharko litzateke, elles sont six heures, lehen esaten zen bezala, eta oraindik esaten den eran: ils sont six, huit, dix, quinze hommes, eta abar. Helburua denbora zehatz bat markatzea besterik ez denez, eta orduetatik bakar bat (hau da, seigarrena), nire pentsamenduak horretara jotzen du, hitzei erreparatu gabe, eta esanarazten dit il est six heures, eta ez elles sont six heures.

Figura horrek, batzuetan, irregulartasunak sortzen ditu generoen kontra, esaterako ubi est scelus qui me perdidit?; edo izenen kontra, esaterako turba ruunt; edo aldi berean bien kontra, esaterako pars mersi tenuere ratem, eta antzekoak.

Diskurtsotik zerbait kentzen duen figurari ELIPSIA edo gabezia deritzo; batzuetan aditza jakintzat ematen delako, hebreeran oso arrunta dena, aditz substantiboa ia beti jakintzat ematen baita; beste batzuetan nominatiboa ematen da jakintzat, esaterako pluit, Deus edo natura pluit esan beharrean; batzuetan adjektiboa adierazita daukan substantiboa, paucis te volo, sup. verbis alloqui; batzuetan beste hitz bat gobernatzen duen hitza, esaterako est Romae, honako hauxe esan beharrean: est in urbe Romae; eta beste batzuetan hitz gobernatua, esaterako, facilius reperias (sup. homines), qui Romam proficiscantur, quam qui Athenas. (Cic.)

Behar baino hitz batzuk gehiago dituen hitz egiteko moduari PLEONASMOA edo oparotasuna deritzo; esaterako, vivere vitam, magis major, eta abar. 
Eta diskurtsoaren ordena naturala iraultzen duena HIPERBATONA edo iraulketa da.

Figura horien guztien adibideak hizkuntza partikularren gramatiketan ikus daitezke, eta batez ere grekoarentzat eta latinarentzat egin diren Metodo Berrietan, horietan zabal samar hitz egin baita figura horietaz.

Gauza bakarra erantsiko dut, ez dagoela gureak baino figura gutxiago erabiltzen duen hizkuntzarik, gureak garbitasuna maite duelako bereziki, eta, ahal den heinean, gauzak ordenarik naturalenean eta nahasgabeenean adieraztea, nahiz aldi berean ez dion uzten beste edozein hizkuntzari aurrea hartzen, ez edertasunean ez dotorezian.

\section{Oharra}

Gramatika honetan ez da hitz egin hitz eratorriez, ezta hitz konposatuez ere, nahiz horiei buruz gauza interesgarri asko dagoen esateko; izan ere, gai horrek zer ikusi handiagoa du Hiztegi orokor batekin Gramatika orokor batekin baino. Baina honako hau ohartaraztea gustatuko litzaiguke: liburu hau lehen aldiz inprimatu zenez geroztik, Logika, edo pentsatzearen Artea izeneko lana azaldu dela, eta printzipio berdinetan oinarritua izaki, gure hau argitzeko asko balio dezakeela eta hemen landu ditugun gauza batzuk frogatzeko ere bai. 